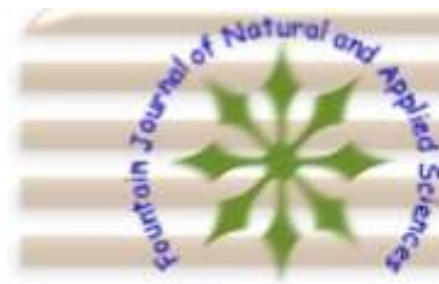

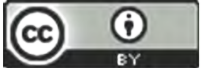

This work is licensed under Creative Commons Attribution 4.0 International License.

DOI: 10.53704/fujnas.v7i1.248

A publication of College of Natural and Applied Sciences, Fountain University, Osogbo, Nigeria.

Journalhomepage:www. fountainjournals.com

ISSN:2354-337X(Online),2350-1863(Print)

\title{
Polyhydroxyalkanoate Producing Potential of Saccharomyces cerevisiae
}

\author{
${ }^{*}$ Jimoh S. O., Akinwande F. O., Ayinde O. A. and Senbadejo, T. Y. \\ Industrial Microbiology Research Laboratory, Microbiology Programme, Department of Biological Sciences, \\ College of Natural and Applied Sciences, Fountain University Osogbo, Osun State, Nigeria.
}

\begin{abstract}
Polyhydroxyalkanoates (PHAs) are inclusion bodies accumulated by some microorganisms as reserve material under unbalanced growth condition such as limited oxygen, nitrogen, phosphorous or sulphur and excess carbon source. Saccharomyces cerevisiae strains were screened for Polyhydroxyalkanoates (PHA) producing potential using plate assay technique with Sudan Black B stain. Saccharomyces cerevisiae efficiency for PHA production was analysed utilizing sawdust as carbon source and the production rate was compared with glucose (control). Thus, PHA synthesising enzymes, PHA carbon chain distributions and concentrations were determined using gas chromatography flame ionization detector (GCFID) while microbial growth (biomass yield) during production was determined using Uv-Visible spectrophotometric technique at $600 \mathrm{~nm}$. PHA was extracted from Saccharomyces cerevisiae cells using solvent extraction technique and the extract was further dissolved using acetone derivatisation process. PHA-synthesising enzymes such as Glyceraldehyde3-phosphate dehydrogenase, Pyruvate dehydrogenase, 3-Ketothiolase, Acetoacetyl-CoA reductase, 3Ketoacyl reductase and Polyhydroxyalkanoate synthase were extracted from cell-free supernatant obtained from glucose and sawdust media. Saccharomyces cerevisiae cells grown in sawdust medium had the highest PHA yield of $75.12 \%$ while $64.66 \%$ PHA was obtained from cells grown in glucose medium. Consequently, utilization of Saccharomyces cerevisiae in limiting condition using agricultural residue could reduce the cost of industrial production of PHA required for plastic production due to its ability to accumulate the polymer intracellularly.
\end{abstract}

Keywords: Saccharomyces cerevisiae, Polyhydroxyalkanoates, Sawdust, PHA synthase

\section{Introduction}

Polyhydroxyalkanoates (PHAs) are naturally occurring storage polyesters produced by a wide range of microorganisms under unbalanced growth conditions (Madison and Huisman, 1999). PHA serves as a carbon and energy source during starvation and is rapidly oxidized thereby retarding the degradation of cellular components (Rawte and Warinkurve, 2002). PHAs are suitable replacements for petrochemical-produced bulk plastics (polyethylene, polypropylene etc.) based on its mechanical properties which include complete degradation to carbondioxide and water through natural microbiological mineralization. Perspectiveareas of PHAs applications aside from non- plastics) include disposable packages (including containers, bottles, and food packaging materials);

${ }^{*}$ Corresponding author: +2348077122762

Email address: olanike771@gmail.com 
in agriculture (systems for prolonged release of fertilizers and agrochemicals); in medicine (medical devices and systems of sustained drug delivery) (Sudeshet al., 2000). The latex of PHAs can be used to produce a water-resistant layer for paper, film or cardboard (Thakoret al., 2006).

Biodegradability and biocompatibility are main characteristics that allow PHAs to be competitive in special market sectors. Poly-3-hydroxybutirate (PHB) and its copolymers such as 3-hydroxyvalerate (3HV) and poly (3-hydroxybutyrate-co-3hydroxyvalerate) (PHBV) are the most known representatives of PHA family. These polyesters are environmentally friendly polymers which can be used in a wide range of agricultural, industrial, and medical applications. Poly- $\beta$ - hydroxybutyrate (PHB) is a thermoplastic with many desirable properties commonly found among the PHA family, is a thermoplastic with many desirable properties (Khanafari et al., 2006). The physical properties of the homopolymer of PHB are similar to those of polypropylene (melting point, crystallinity, glass transition and temperatures), and represents a stiff and brittle material (Thakor et al., 2006). Cost of substrate is a major factor that influences the economics of biodegradable polymer production thus, the aim of the research was to produce biodegradable polymers from inexpensive and renewable carbon sources to improve the production process and lower production cost using Saccharomyces cerevisiae strain.

\section{Materials and Methods}

\section{Pre-treatment and Processing of Sawdust}

Sawdust obtained from Sawmill within Oshogbo Metropolis, Osun state Nigeria was sun-dried, ground into fine powder and filtered to remove residues. Sawdust powder was stored in an air tight container at $30{ }^{\circ} \mathrm{C}$ for further use.

\section{Proximate analysis of sawdust}

Proximate analysis of sawdust such as moisture content, ash content, crude protein, crude fibre, crude lipid and nitrogen-free extracts were determined according to the methodology of $A O A C$, (2005).
Screening for PHA-producing Saccharomyces cerevisiae by Plate assay method

Previously characterised Saccharomyces cerevisiae strains were cultured on yeast-dextrose extract agar for $24 \mathrm{~h}$ and screened for PHA production using Sudan Black B dye (Juan et al., 1998). Ethanolic solution of $0.05 \%$ Sudan Black B was spread over the colonies and the plates kept undisturbed for $30 \mathrm{~min}$. Excess stain was removed from the colonies by washing with $95 \%$ ethanol thus, the dark blue coloured colonies were selected for PHA production.

\section{Production of PHA by Saccharomyces cerevisiae}

PHA production medium per litre [Potassium hydrogen phosphate $(0.4 \mathrm{~g})$, Di-potassium hydrogen phosphate (1.6 g), Magnesium sulphate (0.4 g), Calcium sulphate $(0.2$ g), Ferric chloride (0.004 g)Yeast extract (1.18 g) and Substrate (sawdust; 10 g)] was sterilized at $121^{\circ} \mathrm{C}$ for $15 \mathrm{~min}$ and inoculated with $1.5 \times 10^{8}$ colony forming units (CFU/ml) of Saccharomyces cerevisiae which is equivalent to 0.5 McFarland turbidity standard. The medium was incubated on an orbital shaker at $150 \mathrm{rpm}$ for $96 \mathrm{~h}$ and glucose was used as control (Juan et al., 1998).

\section{Analytic Procedures \\ Determination of Biomass yield}

Uv-Visible Spectrophotometric technique was used to measure the turbidity at $600 \mathrm{~nm}$ at $24 \mathrm{~h}$ interval for $96 \mathrm{~h}$ (Jimoh, et al., 2009). The culture medium was further subjected to serial dilution to determine the number of cells present in the medium.

\section{Assay for PHA-synthesising Enzyme}

Fermented culture medium ( $5 \mathrm{~mL}$ ) was centrifuged for $5 \mathrm{~min}$ at 13,000 rpm and the cellfree supernatant was further concentrated to recover the enzymes in the solid form. Thus, the product recovered was diluted with redistilled methanol and injected into the column of the gas chromatography. The GC condition for the analysis include GC (HP 6890 Powered with HP ChemStation Rev.a09.01 [1206] Software), column type (HP-5), column dimensions $(30 \mathrm{~m} \times 0.25 \mathrm{~mm} \times 0.25 \mu \mathrm{m})$, injection temperature $\left(250^{\circ} \mathrm{C}\right)$, detector signal 
sselected ion mode (SIM), oven program (initial temperature at $60^{\circ} \mathrm{C}$ for $5 \mathrm{~min}$; first ramping at 15 ${ }^{\circ} \mathrm{C} / \mathrm{min}$ for $14 \mathrm{~min}$, maintained for $3 \mathrm{~min}$; second ramping at $12^{\circ} \mathrm{C} / \mathrm{min}$ for $4 \mathrm{~min}$ maintained for $4 \mathrm{~min}$ ), mobile phase/carrier (nitrogen) and nitrogen column pressure (30 psi).

\section{Extraction of PHA}

Culture medium (10 mL) was centrifuged at 10,000 rpm for $15 \mathrm{~min}$; the supernatant was discarded and the pellet was treated with $10 \mathrm{~mL}$ sodium hypochlorite which was incubated at $30^{\circ} \mathrm{C}$ for $2 \mathrm{~h}$. The mixture was further centrifuged at $5000 \mathrm{rpm}$ for 15 min and the pellet was washed with distilled water, acetone and methanol. The pellet was further dissolved in $5 \mathrm{~mL}$ boiling chloroform and evaporated by pouring the solution on sterile slide. The extract was kept in the refrigerator at $4^{\circ} \mathrm{C}$ for further analysis (Khanafari et al., 2006).

\section{Quantification of PHA}

The extract obtained was dissolved using acetone derivatisation process. The derivatisation process was carried out by employing derivatisation reagent (mixture of boron trifluoride and methanol) at $100^{\circ} \mathrm{C}$ for $3 \mathrm{~h}$ to yield methyl esters (Gin-Yu et al., 2014). Derivatised extract was analysed by concentrating the extract to $1 \mathrm{~mL}$ by nitrogen gas steam, thus $2 \mu$ of the extract was injected into the gas chromatography through the injection port. GC condition using HP 6890 machine powered with HP Chem station Rev. A 09.1 (1206) software include injection temperature (split injection), split ratio (20:1), carrier gas (nitrogen), inlet temperature $\left(250^{\circ} \mathrm{C}\right)$, column type (DB-5), column dimensions (30 $\mathrm{m} \times 0.25 \mathrm{~mm} \times 0.25 \mu \mathrm{m}$ ), oven program (initial temperature at $60^{\circ} \mathrm{C}$ for $5 \mathrm{~min}$; first ramping at $15^{\circ} \mathrm{C}$ for $14 \mathrm{~min}$, maintained for $3 \mathrm{~min}$; second ramping at $10^{\circ} \mathrm{C}$ for 5 min maintained for $3 \mathrm{~min}$ ), detector (FID), detector temperature $\left(320^{\circ} \mathrm{C}\right)$, hydrogen pressure (28 psi), nitrogen column pressure (30 psi), and compressed air (12 psi).

\section{Results}

Proximate analysis of sawdust

Portioning of compounds in sawdust into six categories based on the chemical properties of the compounds was determined through proximate analysis. Thus, moisture content, ash content (inorganic residue) crude protein (nitrogen content), crude fibre (quantity of digestible compounds), crude lipid (fat and oil content) and soluble carbohydrates (nitrogen-free) content of sawdust are as presented on table 1 . The results are mean of triplicate analysis.

\section{Rapid Detection of PHA producing Saccharomyces cerevisiae}

The granules of PHA producing Saccharomyces cerevisiae cells absorbed $0.05 \%$ alcoholic solution of Sudan Black $B$. Thus, colonies unable to incorporate Sudan Black B i.e non-PHA producers appeared whitish, while PHA producers appeared bluish black. Blue black colony with the widest magnitude of stain was selected for production.

\section{Determination of Biomass yield}

Biomass yield obtained at $24 \mathrm{~h}$ interval during PHA production for $96 \mathrm{~h}$ are as shown on figure 1 . The biomass yield of sawdust medium at the end of fermentation was $1.178 \mathrm{OD}\left(2.8 \times 10^{8} \mathrm{CFU} / \mathrm{ml}\right)$ while glucose medium had 0.356 OD $\left(1.7 \times 10^{8} \mathrm{CFU} / \mathrm{ml}\right)$.

\section{Quantification of PHA synthesising-Enzymes}

PHA synthesising enzymes extracted from the production media (glucose and sawdust media) include Glyceraldehyde-3-phosphate dehydrogenase, Pyruvate dehydrogenase, 3-Ketothiolase, Acetoacetyl-CoA reductase, 3-Ketoacyl reductase and Polyhydroxyalkanoate synthase (table 2).

Table 1: Proximate Composition of Sawdust

\begin{tabular}{ll}
\hline Parameter & $\begin{array}{l}\text { Composition (\%) } \\
\text { (Mean } \pm \text { SD) }\end{array}$ \\
\hline Moisture content & $11.0 \pm 0.22$ \\
Ash content & $12.3 \pm 1.17$ \\
Crude fibre & $50.0 \pm 1.58$ \\
Crude protein & $0.12 \pm 0.01$ \\
Crude lipid & $8.14 \pm 0.35$ \\
Nitrogen free extract & $18.3 \pm 1.29$ \\
\hline
\end{tabular}




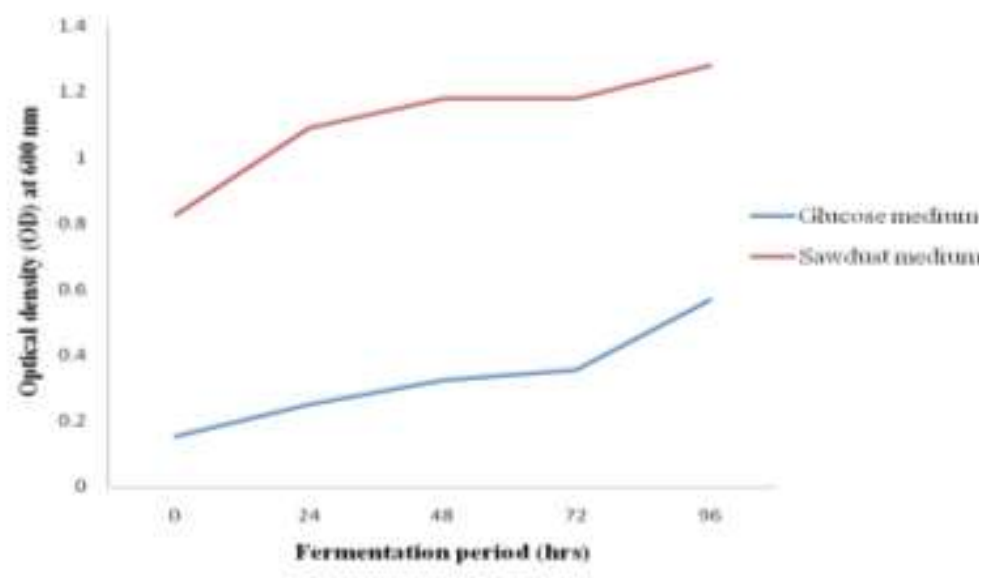

Figure 1. Biomass yield during PHA production

Table 2: Quantification of PHA synthesising- Enzymes

Sawdust medium

Glucose medium

\begin{tabular}{ccccl} 
RetTime [min] & $\begin{array}{c}\text { Amount } \\
{[\mathrm{mg} / \mathrm{g}]}\end{array}$ & $\begin{array}{c}\text { RetTime } \\
{[\mathrm{min}]}\end{array}$ & $\begin{array}{c}\text { Amount } \\
{[\mathrm{mg} / \mathrm{g}]}\end{array}$ & Enzyme \\
\hline 12.366 & $4.99313 e-5$ & 12.314 & $4.98448 \mathrm{e}-5$ & $\begin{array}{l}\text { Glyceraldehyde-3-Phosphate } \\
\text { Dehydrogenase }\end{array}$ \\
13.866 & $2.04939 e-5$ & 13.823 & $2.06319 e-5$ & Pyruvate Dehydrogenase Complex \\
15.400 & $3.57889 e-5$ & 15.389 & $3.58481 e-5$ & 3-Ketothiolase \\
16.300 & $1.78941 e-5$ & 16.247 & $1.78950 e-5$ & Acetoacetyl-CoA Reductase \\
18.055 & $1.09595 e-4$ & 17.698 & $1.60305 e-4$ & 3-Ketoacyl Reductase \\
18.936 & $5.17809 e-3$ & 18.959 & $1.45950 e-4$ & PHA synthases \\
Total amount of & $\mathbf{5 . 4 1 1 7 9 e - 3}$ & & $\mathbf{4 . 3 0 4 7 5 e - 4}$ & \\
Enzyme (mg/g) & & & &
\end{tabular}

\section{Quantification of Polyhydroxyalkanoates}

Varying concentrations of PHA such as Poly(3hydroxybutyrate), Poly(3-hydroxyvalerate), Poly(3hydroxyhexanoate), Poly(3-hydroxyheptanoate), Poly(3-hydroxyloctanoate, Poly (3hydroxylnonanoate, Poly(3-hydroxydecanoate), Poly(3-hydroxyundecanoate), Poly(3hydroxydodecanoate), Poly(3-hydroxytridecanoate), Poly(3-hydroxytetradecanoate), hydroxypentadecanoate) and Poly(3hydroxyhexadecanoate) extracted from glucose and sawdust media are as shown on table 3 .

\section{Discussion}

Plastics produced by the petrochemical industry are not biodegradable and therefore accumulate in the environment resulting to environmental pollution (Juang and Chiou, 2007). Stringent necessity to replace conventional plastics with biodegradable products obtained by renewable sources is importance due to the negative impact of plastics manufacturing, their extreme prolonged degradation period and the low recycling rate. The carbon sources for producing PHAs have been biorefinery byproducts of hemicellulose hydrolysates, crude glycerol, waste plant oils and low-grade biodiesel 
Fountain Journal of Natural and Applied Sciences 2018; 7(1): 42-47

Table 3: PHA extracted from Saccharomyces cerevisiae cells

\begin{tabular}{|c|c|c|c|c|}
\hline \multicolumn{2}{|c|}{ Glucose medium } & \multicolumn{2}{|c|}{ Sawdust medium } & \multirow[b]{2}{*}{ Polyhydroxyalkanoates } \\
\hline $\begin{array}{l}\text { RetTime } \\
\text { [min] }\end{array}$ & $\begin{array}{l}\text { Amount } \\
{[\mathrm{g} / 100 \mathrm{~g}]}\end{array}$ & $\begin{array}{l}\text { RetTime } \\
\text { [min] }\end{array}$ & $\begin{array}{l}\text { Amount } \\
{[\mathrm{g} / 100 \mathrm{~g}]}\end{array}$ & \\
\hline 15.022 & 54.98723 & 15.035 & 63.84663 & Poly (3-Hydroxybutyrate) \\
\hline 16.707 & 9.61345 & 16.725 & 11.24933 & Poly (3-Hydroxyvalerate) \\
\hline 17.346 & $5.78452 e-3$ & 17.369 & $2.02187 e-3$ & Poly (3-Hydroxyhexanoate) \\
\hline 17.667 & $9.80213 e-4$ & 17.687 & $5.07718 e-4$ & Poly (3-Hydroxyheptanoate) \\
\hline 17.916 & $2.82371 e-3$ & 17.935 & $1.14084 e-3$ & Poly (3-Hydroxyoctanoate \\
\hline 18.351 & $1.25638 e-5$ & 18.367 & $3.09838 e-6$ & Poly (3-Hydroxynonanoate) \\
\hline 18.776 & $1.33038 e-2$ & 18.795 & $3.91868 e-3$ & Poly (3-Hydroxydecanoate) \\
\hline 19.305 & $9.87839 e-3$ & 19.329 & $2.55811 e-3$ & Poly (3-Hydroxyundecanoate) \\
\hline 19.784 & $2.46552 e-3$ & 19.806 & $1.05958 e-3$ & Poly (3-Hydroxydodecanoate) \\
\hline 20.425 & $7.58756 e-3$ & 20.352 & $2.80123 e-3$ & Poly (3-Hydroxytridecanoate) \\
\hline 21.156 & $6.55639 e-3$ & 20.829 & $3.71543 e-3$ & Poly (3-Hydrotetradecanoate) \\
\hline 21.825 & $5.59959 e-3$ & 21.843 & $1.92384 e-3$ & Poly (3-Hydroxypentadecanoate) \\
\hline 23.485 & $7.80676 e-3$ & 23.504 & $2.49051 e-3$ & Poly (3-Hydroxyhexadecanoate) \\
\hline $\begin{array}{l}\text { Total amount of } \\
\text { Polyhydroxyalka- } \\
\text { noates }(\mathrm{g} / 100 \mathrm{~g})\end{array}$ & 64.66348 & & 75.11810 & \\
\hline
\end{tabular}

but this research shows that sawdust is a potentially sustainable substrate for PHA production. Microorganisms generally produce a variety of polymer as survival mechanism in nature. These polymers are important sources of biodegradable raw materials used in production of materials such as plastic, absorbents, biomedical materials and tissue engineering materials. Various bacteria were reported to have the capacity to produce PHA polymer intracellularly with little research using yeast.

PHA biosynthesis is a NADPH-dependent pathway which requires acetyl-coenzyme-A (acetylCoA) formed from catabolising carbohydrate through Entner-Doudoroff pathway (Li et al., 2009) thus varying concentrations of enzymes obtained in this study showed that Saccharomyces cerevisiae expressed the genes responsible for synthesis of the biosynthetic enzymes namely $\beta$-Ketothiolase, Acetoacetyl-COA reductase and PHA synthase required for the accumulation of PHA under unbalanced growth conditions (excess amount of carbon source) as reported by Verlindenet al., (2007). The proximate composition of the sawdust and variation in biomass yield indicated that sawdust contain appreciable amounts of nutrients required for the growth of S. cerevisiae and PHA production.
Accumulation of PHA intracellularly is a direct reflection of Saccharomyces cerevisiae ability to synthesize PHA from sawdust and glucose. PHA granules serves as a store of carbon and energy; and as an electron sink into which excess reducing power can be channelled. Thus, variation in the PHA concentration obtained from Saccharomyces cerevisiae grown in sawdust and glucose media was due to the rate of expression of NADH because in such limiting condition, NADH increases, inhibiting the citrate synthase and isocitrate dehydrogenase activities of the tricarboxylic acid cycle and increase in acetyl COA levels, resulting to PHA synthesis (Diaz-Barrera and Soto, 2010).

Furthermore, high PHA concentration $(75.12 \%)$ obtained from Saccharomyces cerevisiae cells grown in sawdust medium after $96 \mathrm{~h}$ compared to $42.26 \%$ reported by Aravindet al., (2012) showed that $S$. cerevisiae is a promising microorganism for industrial production of PHA rather than Ralstonia eutrophus recommended by some researchers which implied that S. cerevisiae can synthesize PHA polymer under unbalanced condition. PHA yield of $64.66 \%$ obtained from Saccharomyces cerevisiae cells grown in glucose medium may be due to absence of carbon and energy sources as the fermentation period increases because PHA producers have the ability to utilize 
Fountain Journal of Natural and Applied Sciences 2018; 7(1): 42-47

PHA as their carbon source under stressful condition.

Based on the result obtained in this research, sawdust will be an economically and environmentally friendly raw material for industrial scale PHA production using Saccharomyces cerevisiae. Thus, sawdust is recommended for industrial production of plastic materials, packages, absorbents, biomedical materials, tissue engineering materials and as a replacement for petrochemically synthesized materials due to the availability of plant residue. It will increase the quantitative and qualitative characteristics of products due to the fact that PHAs are produced from renewable sources which are biodegradable and also have multiple applications in modern biotechnologies. Its utilization will also improve the state of the environment by solving the problems of solid waste management that results from accumulation of sawdust thus saving the environment from air pollution caused by its recycling.

\section{References}

AOAC (2005). Association of Official's Analytical Chemists. Official Methods of Analysis, $18^{\text {th }}$ edition, Washington D.C-USA.

Aravind, J., Sasikala, P., \& Preethi, R. (2012). Production of Polyhydroxyalkanoate (PHA) using hydrolyzed grass and Syzygiumcumini seed as low cost substrates. Journal of Microbiology and Food Sciences, 2(3):970-982.

Díaz-Barrera, B., \& Soto, E. (2010). Biotechnological uses of Azotobactervinelandii: Current state limits and prospects. African Journal of Biotechnology, 9(33):5240-5250.

Giin-Yu, A. T., Chia-Lung, C., Ling, L., Liya, G., \& Lin, $W$. (2014). Start a research on biopolymer polyhydroxybutyrate (PHB): Journal of Polymers, 6:706-7054.

Jimoh, S.O., Ado, S. A., \& Ameh, J. B. (2009). Simultaneous Saccharification and Fermentation of Yam Peel to Ethanol by coculture of Aspergillus niger and Saccharomyces cerevisiae. Biological and Environment Sciences Journal for the Tropics, 6(1):96 - 100.

Juan, M. L., Gonzalez L. W., \& Walker, G. C. (1998). A Novel Screening Method for Isolating Exopolysaccharide deficient Mutants. Journal of Applied and Environmental Microbiology, 64:4600-4602.

Juang, D. F., \& Chiou, L. J. (2007). Microbial population structures in activated sludge before and after the application of synthetic polymer. International Journal of Environmental Science and Technology, 4 (1):119-125.

Khanafari, A., Sepahi, A. A., \& Mogharab, M. (2006). Production and recovery of poly $\beta$ hydroxybutyrate from whey degradation by Azotobacter. Iranian Journal of Environment and Health Science Engineering, 3 (3):193-198.

Li, Z.J., Cai, L., Wu, Q., \& Chen, G.Q. (2009). Overexpression of NAD kinase in recombinant Escherichia coli harboring the phbCABoperon improves poly(3-hydroxybutyrate) production. Journal of Applied Microbiology and Biotechnology, 83: 939-947.

Madison, L. L., \& Huisman, G.W. (1999). Metabolic engineering of poly(3 hydroxyalkanoates): from DNA to plastic. Microbiology Molecular Biology Reviews, 63: 21-53.

Rawte, T., \& Mavinkurve, S.A. (2002). Rapid hypochlorite method for the extraction of polyhydroxyalkanoates from bacterial cells. Indian Journal of Experimental Biology, 40:924-929.

Sudesh, K., Abe, H., \& Doi, Y. (2000). Synthesis, structure and properties of polyhydroxyalkanoates: Biological polyesters. Prog Polymer Science, 25:1503-1555.

Thakor, N., Trivedi, U., \& Patel, K. C. (2006). Microbiological and Biotechnological aspects of biodegradable plastics: Polyhydroxyalkanoates. Indian Journal of Biotechnology, 5 (2):137-147.

Verlinden, R., Hill, D., Kenward, M., Williams, C., \& Radecka, I. (2007). Bacterial synthesis of biodegradable polyhydroxyalkanoates. Journal of Applied Microbiology, 102:1437-1449. 